\title{
Endoscopic Interlaminar Discectomy Using Simple Technique Without the use of Complicated Industrial Tubular Systems
}

\author{
MOHAMMED H. EL-TANTAWY, M.D. \\ The Department of Neurosurgery, Faculty of Medicine, Benha University, Egypt
}

\begin{abstract}
Background: The fully endoscopic and microscopic discectomy are the most widely used minimally invasive spine decompression techniques nowadays. All Different techniques have been described in the literature for the fully endoscopic lumbar discectomy using tubular systems were used with a limitation of work.

Objective: To assess our modified surgical technique of endoscopic interlaminar discectomy using simple port, custom made, and the ordinary sinoscope without the use of complicated industrial tubular systems.

Study Design: This study is a retrospective clinical study included fifteen patients with unilateral radiculopathy due to L4-5, L5-S 1 disc herniation and unilateral lateral recess stenosis, underwent endoscopic decompression surgery using our technique in the period from May 2013 to September 2015 at Neurosurgery Department, Benha University Hospital. The mean period of follow-up was $25.05 \pm 3.79$ months.
\end{abstract}

Methods: Analysis was performed with the use of pain intensity and functional outcome assessment scales before and after surgery. Complications and radiographic findings were analyzed.

Results: Fifteen patients were studied, nine males $(60 \%)$ and six females $(40 \%)$ with mean age $45.5 \pm 8.66$ (ranging from 21-65 years). Leg pain was reduced from an average NRS of 8.5 preoperatively to $1,0.5$, and 0.3 at 1,2 and 4 weeks post operatively. Pre operative low back pain improved from an average NRS of 7.6 to 2,1 and 0.5 at 1,2 and 4 weeks postoperatively The average QDS reduced from 58 to 35,20 and 16 at 1,2 and 4 weeks postoperatively.

Conclusion: The endoscopic interlaminar discectomy is an efficient surgical technique for management of unilateral radiculopathy caused by lumber disc herniation and lateral recess stenosis using simple tools without the need for highly expensive endoscopic spine tubular systems offered by the spine companies.

Key Words: Endoscopic-Interlaminar discectomy.

\section{Introduction}

THE main goal of any spine surgery is to get adequate decompression of neural structures with

Correspondence to: Dr. Mohammed H. El-Tantawy, E-Mail: hammad neurosurg@yahoo.com. preserving the most important structures for stability of the spine including; muscles, facet joints, ligaments and bone [1]

Minimally invasive spine surgery techniques achieved this goal through providing less traumatic, faster, shorter surgery duration, less painful recovery and better short and long term results [2].

The fully endoscopic and microscopic discectomy are the most widely used minimally invasive spine decompression techniques nowadays. Many reports have shown comparable results of both techniques in lumber discectomy and decompression surgery [3-5]

Different techniques have been described in the literature for the fully endoscopic lumbar discectomy. All of them used tubular systems manufactured by spine companies; each system has its limitation of work and sophisticated way of use in addition to the obligation to use their endoscopic system [6-9]

In this study we described our modified surgical technique in of endoscopic interlaminar discectomy using simple port custom made from $20 \mathrm{cc}$ syringe and using our ordinary sinoscope without the use of complicated industrial tubular systems.

\section{Patients and Methods}

This study is a retrospective clinical study included fifteen patients with unilateral radiculopathy due to L4-5, L5-S 1 disc herniation and unilateral lateral recess stenosis, underwent endoscopic decompression surgery using our technique in the

\footnotetext{
Abbreviation:

MRI: Magnetic Resonance Imaging.

NRS: Numerical Rating Score.

QDS: Quebec back pain disability scale.

CT : Computerized Tomography.
} 
period from May 2013 to September 2015 at Neurosurgery Department, Benha University Hospital.

\section{Patient population:}

There were nine males $(60 \%)$ and six females (40\%) with mean age $45.5 \pm 8.66$ and range 21-65 years involved in this study as shown in Table (1).

Table (1): Patients' demographics.

\begin{tabular}{ll}
\hline Patients (15) & No. $(\%)$ \\
\hline Sex: & \\
Female & $6(40.0 \%)$ \\
Male & $9(60.0 \%)$ \\
Aetiology: & \\
L5-S1 disc & $7(46.7 \%)$ \\
L4-L5 disc & $6(40.0 \%)$ \\
Lateral recess stenosis & $2(13.3 \%)$ \\
Age (years): & \\
Mean \pm SD & $45.5 \pm 8.66$ \\
Range & $21-65$ \\
Follow-up period (months): & \\
Mean \pm SD & $25.05 \pm 3.79$ \\
Range & $16-36$ \\
\hline
\end{tabular}

Preoperative work-up:

All patients reported in this study presented with signs and symptoms of unilateral radicular compression due to lumber disc herniation or lateral recess stenosis. All of them were unresponsive to conservative treatment for at least 2 months. The diagnosis was made based on clinical examination compatible with L5 or S 1 radiculopathy. The diagnosis has been confirmed by Magnetic Resonance Image (MRI) to the lumbosacral region. Positive radicular compression on MRI scan has been demonstrated matching the clinical finding of the patient.

Patients with more than one disc level, patients with extra foraminal disc and patients with segmental stenosis have been excluded from this study. Informed consent was obtained from patients prior to surgery. Pain intensity and functional impairment were assessed preoperatively.

\section{Surgical technique:}

Patient positioned lateral with complaining side up with his body rotated 30 degrees away from the surgeon. Maintaining this position is made by flexing the upper leg while extending the lower one. The lower arm should be extended forward with soft silicon bad in the lower arm bit to protect compression of the brachial plexus against the table Fig. (1A).
Localization of the disc level is done by 2 spinal needles, one is inserted perpendicular to the lamina at midline just flush with the spinous process Fig. (1B). Intra operative $\mathrm{C}$ armed image tube is then used to ensure the localization at disc level by rotating the tube 30 degrees to get dead lateral image Fig. (1F). The 2 nd needle is then inserted perpendicular to the 1 st one, so that both tips touch each other at the facet joint Fig. (1B). This needle will be used later on to confirm accurate level during surgery Fig. $(1 \mathrm{C})$. Now the ${ }^{1 \text { st }}$ needle can be removed and the mid line is marked together with the incision line which is made $20 \mathrm{~mm}$ length perpendicular to the midline with its lower end reaching the spinous process and the upper end in line with the 2 nd needle Fig. (1C).

After the skin is prepped and the toweling is done, we cut the skin and subcutaneous tissue sharply and with electrocautary until we reach the lumber fascia. Then we palpate with the index finger the spinous process and with sharp tip scissor we puncture the fascia by sliding the scissor on the spinous process surface. This puncture is then widened only to accommodate the port. Then with small periosteal elevator we gently and do subperiosteal separation of the muscle from the lamina to prepare a place for introduction of the port, which is made from $20 \mathrm{cc}$ syringe custom made by cutting its upper part and making $\mathrm{v}$ shaped slit on its edge Fig. (1E) which is used to palpate the spinous process with Penfield to locate the midline. The length of the designed port (syringe) is made according to the depth measured from the skin to the lamina.

Insertion of the port is then made by rotating the barrel of the syringe in, with holding the plunger of the syringe (act now as a trochar) by the medial 2 fingers until we reach the lamina Fig. (1E).

The scope holder is anchored to the operating table about $50 \mathrm{~cm}$ caudal to the incision, to use all the joints of the holder freely and get maximum benefit from scope navigation Fig. (1D). The scope is then attached to the holder and introduced in the rostral part of the field leaving the caudal part for working by both hands with the suction and the other instrument Fig.(2A \& B). The correct position of the port is then confirmed by watching the tip of the of the needle touching the facet, and the midline is confirmed by palpating the spinous process surface with a Penfield through the $\mathrm{v}$ shaped slit in the port Fig. (2A \& B). 


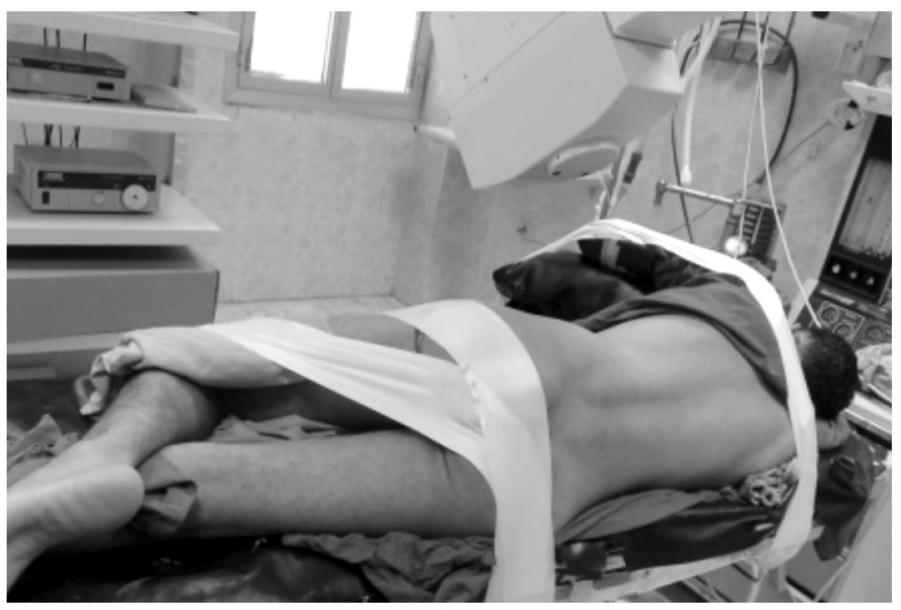

(A)

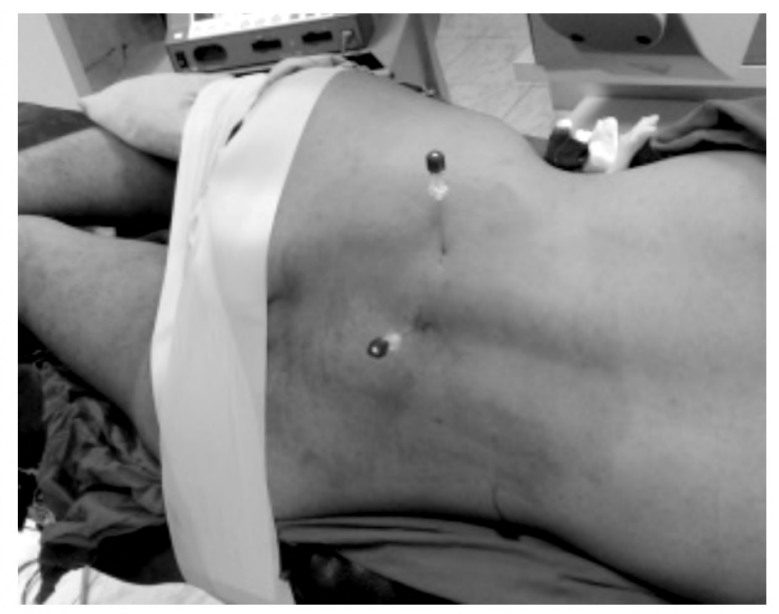

(B)

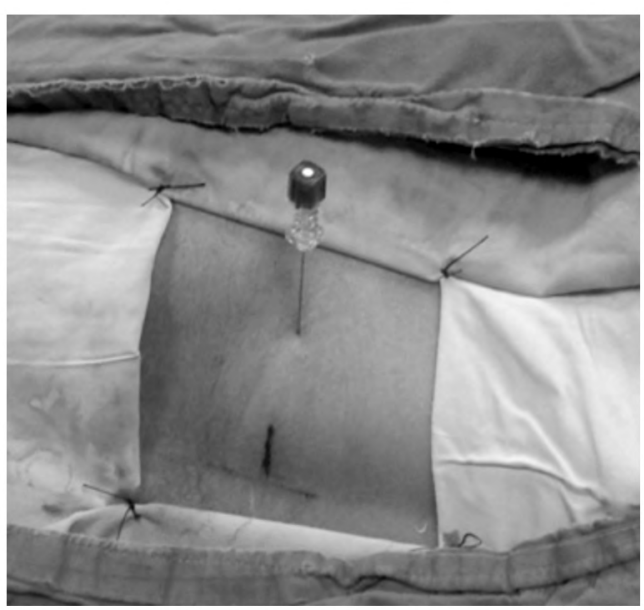

(C)

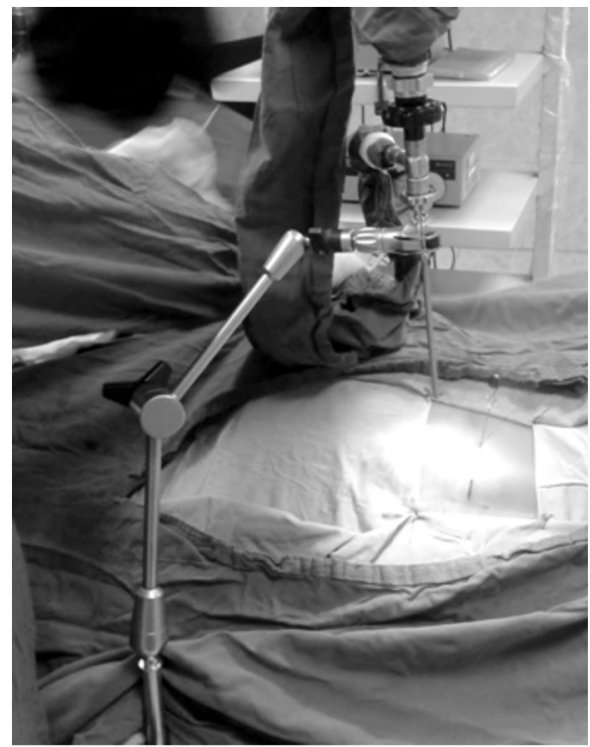

(D)

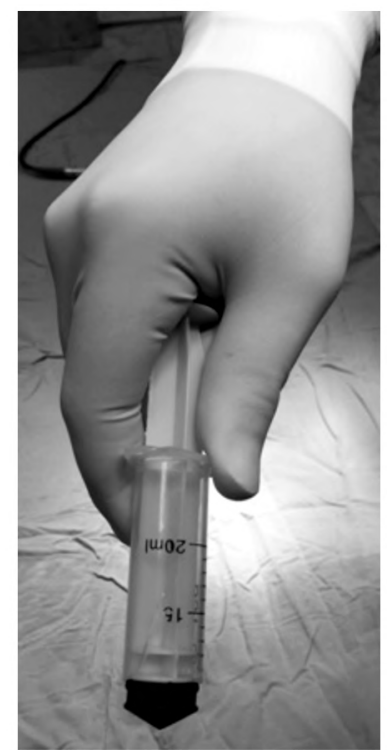

(E)

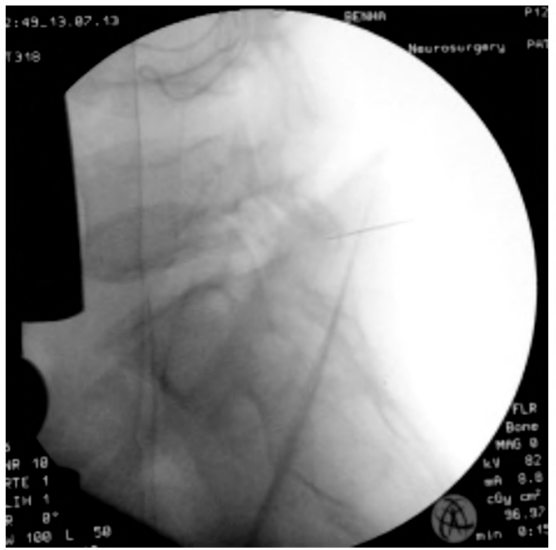

(F)

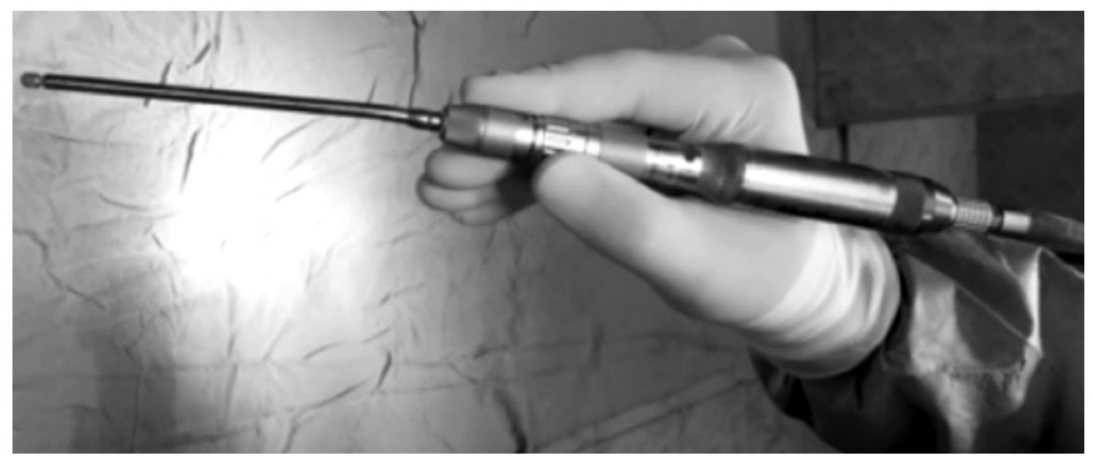

(G)

Fig. (1): (A) Patient position. (B) 2 spinal needles for localization. (C) Marking the incision line. (D) Attachment of the scope holder to the table. (E) Inserting the custom made port. (F) C-Arm image for the localization. (G) The drill with the telescopic attachment. 

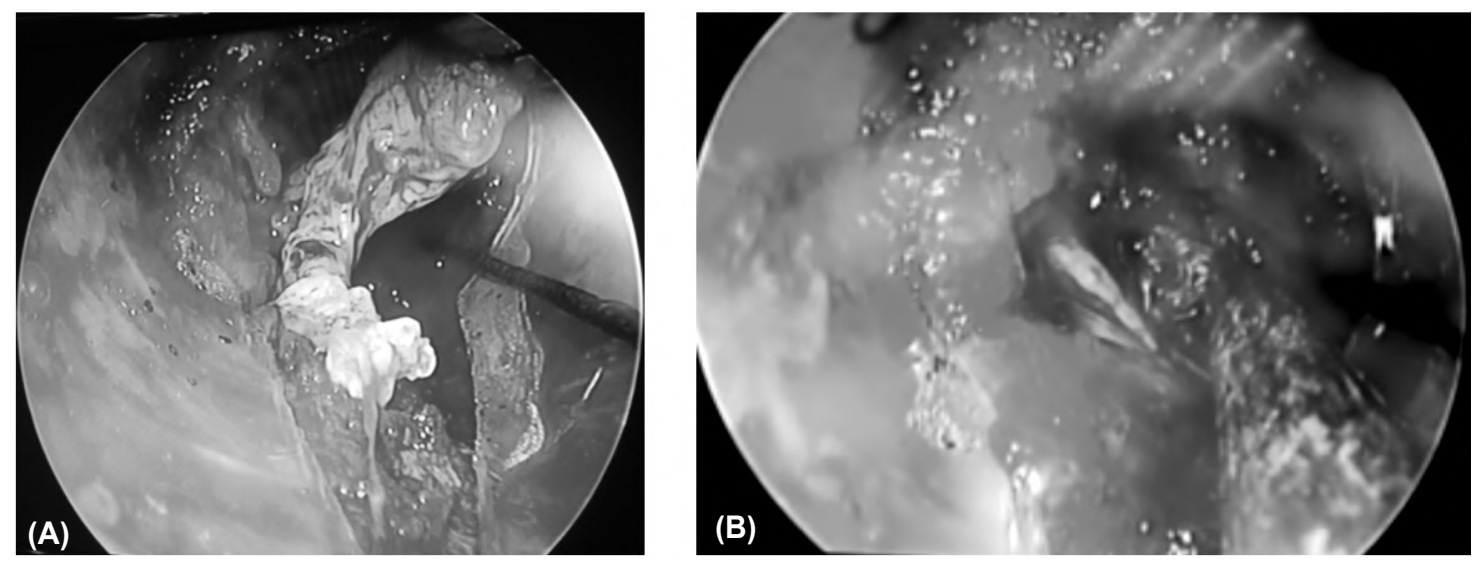

Fig. (2): Intra operative endoscopic picture showing. (A) Disc fragment removal through the port [note the V shaped slit at the edge of the port for midline identification. (B) After removal of the disc and decompression of the nerve root.
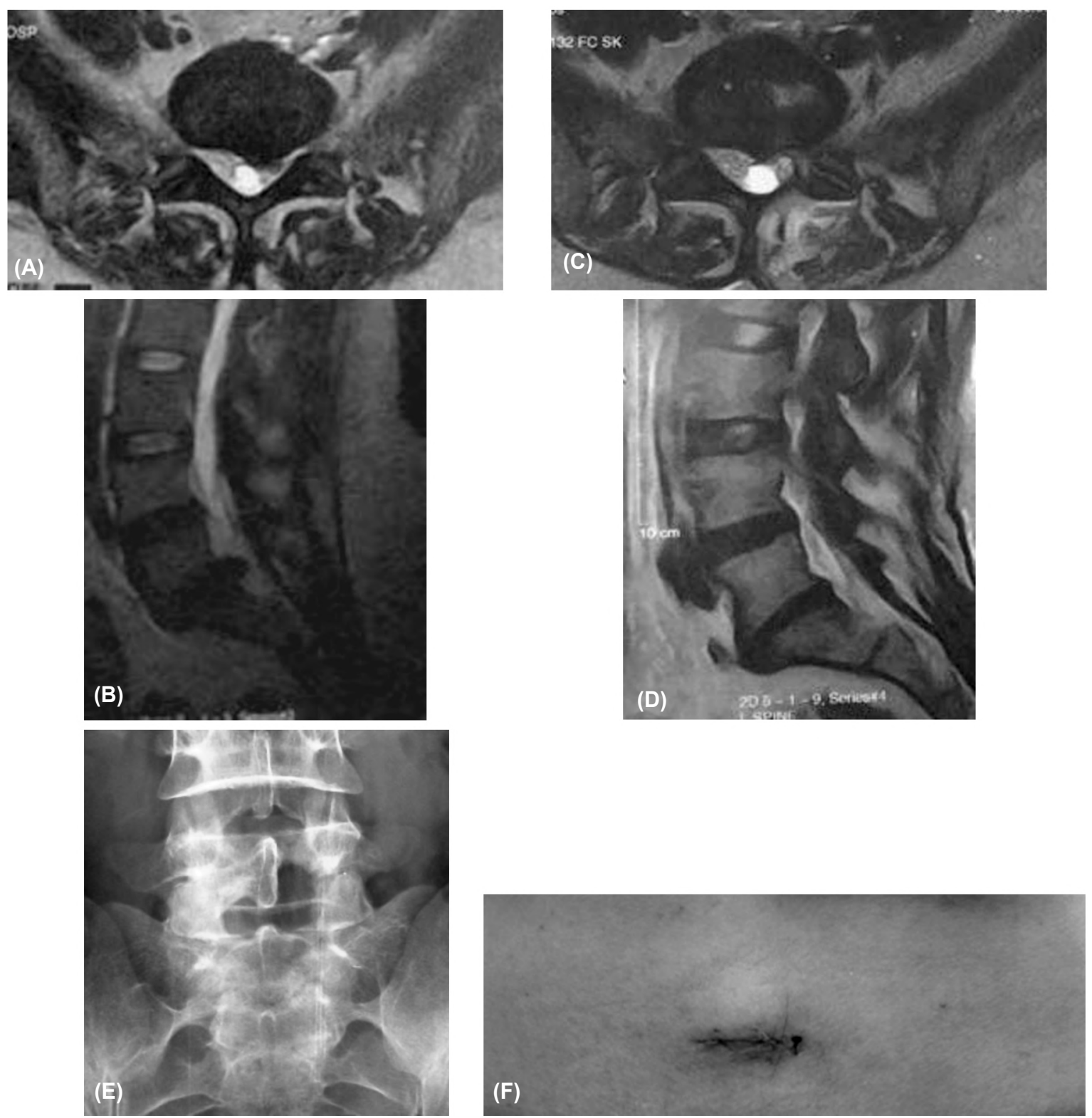

Fig. (3): MRI scan showing (A) axial T2 preoperative L5-S1 left disc herniation. (B) Pre operative sagittal T2 MRI scan for thesame patient. (C) Axial T2 post operative showing disc removal. (D) Sagittal T2 MRI for the same patient. (E) A$\mathrm{P}$ X-Ray on lumbar spine showing the fenestration after endoscopic discectomy. (F) Skin closure after surgery. 
The shaggy remaining muscle fiber is then cautarized and removed to identify the lamina. Then we use the telescopic Midas Rex drill attachment made by Medtronic Fig. (1G) to drill the lower part of the lamina until we reach the upper border of the yellow ligament. Removing the ligament will explore the root, disc space and medial part of the thecal sac. After removing the disc, we use the panoramic view of the endoscope to explore the disc space and the field for any residual part of the disc by changing the angles and position of the scope through the multi joint scope holder Fig. (2B).

We use our regular sinoscope which is $18 \mathrm{~cm}$ length and $4 \mathrm{~mm}$ diameter, cleaning the tip of the scope is done by irrigating with worm Saline. At the end of surgery remove the port and ensure hemostasis by burning the bleeding point of the muscle during taking the scope out. One stitch is then made to approximate the fascia and subcuticular closure of the skin is made without drain Fig. $(3 \mathrm{~F})$.

Patients were discharged on the ${ }^{1 \text { st }}$ post operative day, prophylactic antibiotics were given for 2 days with simple analgesics for 5 days post operative. Patients were asked to ambulate from bed 2 hours after full recovery and advised to avoid weight lifting and sitting for long time for 2 weeks. Walking was encouraged.

\section{Postoperative work-up:}

Pain intensity and functional impairment were reassessed postoperatively and at ${ }^{1 \mathrm{st}}$ post operative day then at the end of the 1 st, 2 nd and 4 th week postoperatively. Leg and low back pain were quantified through the numerical rating score (NRS). Functional outcome assessment was made using the Quebec back pain disability scale questionnaire (QDS). Patients were followed clinically and radiologically through a period ranging from 16 to 36 months with a mean of $25.05 \pm 3.79$ months. All intraoperative complications, persistence of preoperative complain, surgical time and total blood loss and clinical state postoperatively were collected and reviewed.

Postoperative MRI scans on lumbosacral region were done for all patients after 6 months and if any recurrence of symptoms occurred.

\section{Results}

The study included seven patients $(46.7 \%)$ with L5-S 1 unilateral disc herniation and six patients
(40\%) with L4-5 disc herniation, those patients underwent endoscopic discectomy. The study also included two patients (13.3\%) with unilateral recess stenosis who underwent endoscopic decompression only.

Radicular pain and parathesia were the main presenting symptoms in all cases.

The average preoperative NRS for leg pain in this study was 8.5 and for back pain was 7.6 while the preoperative mean QDS was 58 .

The average operating time was 75 minutes (range 65-90 minutes) and the average blood loss was $30 \mathrm{cc}$.

One endoscopic procedure was converted to microscopic with widening of the wound due to occurrence of dural tear that necessitated dural repair. Another patient developed small epidural blood collection appeared on MRI scan postoperatively, he was diagnosed when he noticed some unusual numbness in both legs. This patient managed conservatively, no surgical evacuation was needed.

No other operative complications were reported as nerve tissue damage, postoperative CSF leak, wound infection or worsening of the neurological state of the patient.

Leg pain was significantly reduced from an average NRS of 8.5 preoperatively to $1,0.5$, and 0.3 at 1,2 and 4 weeks post operatively (Chart 1 ). Pre operative low back pain improved from an average NRS of 7.6 to 2,1 and 0.5 at 1,2 and 4 weeks postoperatively (Chart 2).

The functional recovery was significantly improved in all patients. The average QDS reduced from 58 to 35,20 and 16 at 1,2 and 4 weeks postoperatively (Chart 3).

11 patients $(73.4 \%)$ used pain medications postoperatively for 5 days while 4 patients $(26.6 \%)$ continued to use them for 10 days.

During the 16 months average follow-up period, 2 patients (13.3) showed recurrent disc fragments on MRI, one of them developed symptoms at 6 months of follow-up and the other was discovered accidentally when he did his MRI follow-up at 1 year. The first patient underwent another microscopic surgery. The other one was just followed and no surgery was needed until the end of the follow-up period. 


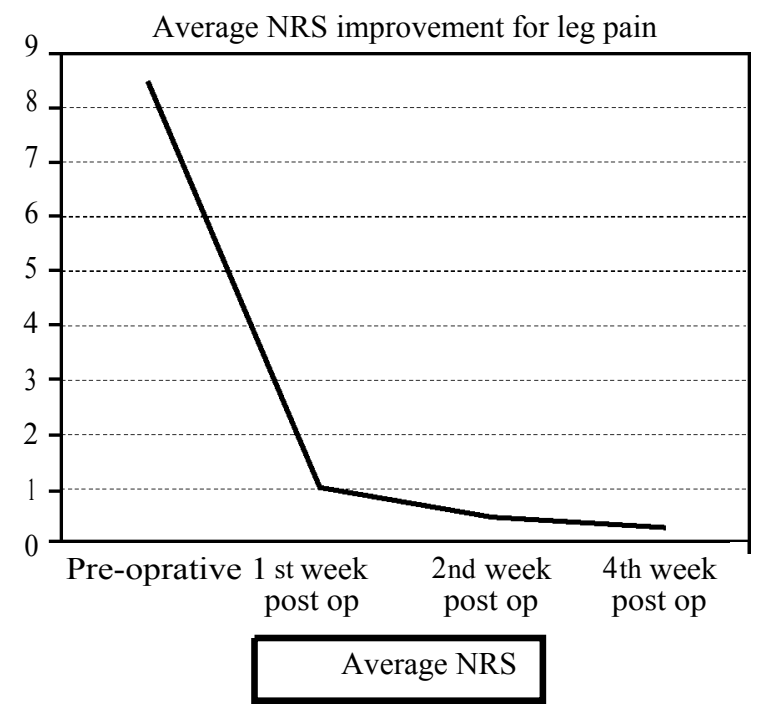

Chart (1): Improvement of leg pain

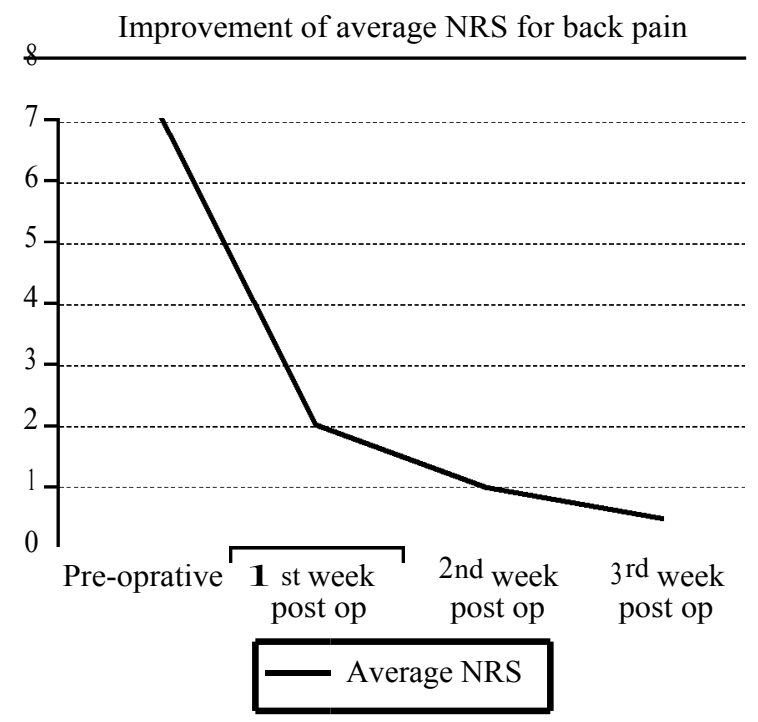

Chart (2): Improvement of back pain

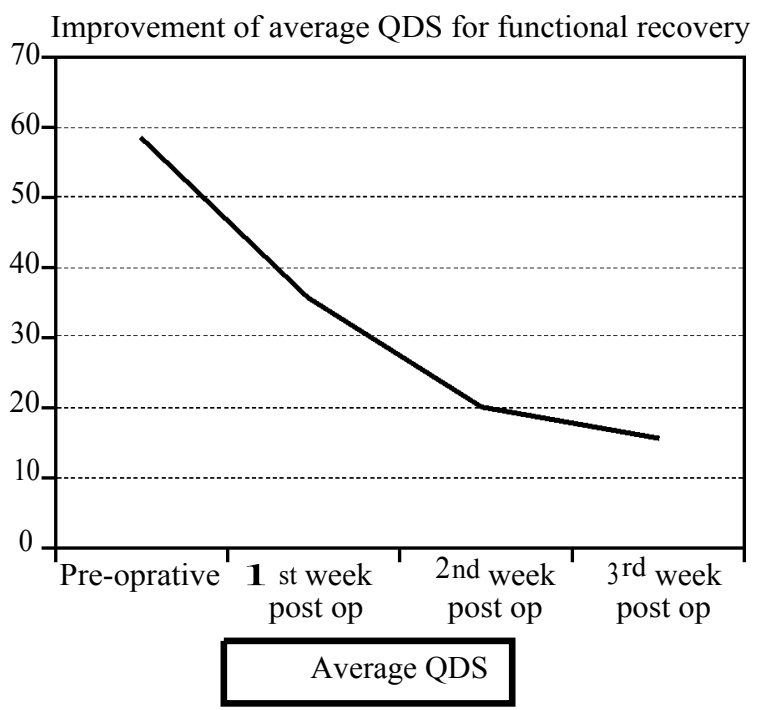

Chart (3): Improvement of functional disability.

\section{Discussion}

Mixter and Barr were the 1 st to perform open laminectomy and discectomy in 1934. Since then, this surgery had become the gold standard surgical procedure in the treatment of lumber disc herniation $[10,11]$

This surgical procedure has been changed and refined over time quickly. In late 1960s Yasargil introduced the operating microscope in spine surgery and he introduced the term standard open microsurgical discectomy. In 1997 Foly introduced the tubular retractor system and endoscopy aided spine through interlaminar approach. He named the technique micro endoscopic discectomy. This minimally invasive technique uses trans-muscular approach through which tubular system is introduced together with the scope [9]

With the advancement in the endoscopic tools and the popularity of endoscopic techniques in spine surgery, the procedure became more minimally invasive and the term" percutaneous endoscopic interlaminar discectomy" evolved with the transforaminal variant. This percutaneous technique depends on directly targeting the disc fragment with very minimal work on ligaments or bone. Although this technique is associated with minimal tissue damage but still not suitable for large migrated fragments and associated with higher recurrence rate, also it is difficult with this technique to achieve sufficient decompression in cases of lumber stenosis [8]

Generally speaking endoscopic spine surgery has the advantages of less tissue dissection, reduced blood loss, minimal epidural fibrosis, less hospital stay, early functional recovery, improvement in quality of life, better cosmoses and less cost of treatment [8]

Different types of widely used endoscopic discectomy systems are provided by large spine companies. Most of them depend mainly on tubular retractor systems with the scope anchored to them. METRx system, produced by Medtronic Sofamor Danek (Memphis USA), although has several advantages including decreased endoscopic diameter and variable tubular retractor sizes, still has limitation specially regarding the tubular retractor (Xtube) and the flexible arm assembly needed [7]

The vertebroscope provided by Zeppelin company (Zeppelin-instruments, Pullach, Germany) has a tubular geometry with limited working space that necessitate the use of specially designed micro instruments provided by the company [7]. 
In Destandau system, by Carl Storz Germany, the surgeon has to hold the tube while performing the procedure with one hand only. This was followed by Easy Go II system to solve this problem [12].

In 2004 special flexible retractor system called Spine Gate (Geister Medizntechnik, Tuttlingen, Germany) was introduced as a novel retractor for endoscopic spine interventions, although this retractor solved some problems associated with tubular systems, it has many sophisticated parts and did not show any popularity [7] .

Because of all these technical limitations of the currently commercially available tubular retractor systems and the unnecessary high cost of these systems, we performed successfully the endoscopic technique with simple syringe tube designed in length according to individual patient, with the use of our ordinary sinoscope and scope holder without the need for any specially made endoscopic spinal instruments.

Our technique involved certain steps that differ from other methods of endoscopic spine surgery. Positioning the patient lateral with 30 degrees tilt away from the surgeon instead of prone position that has been used by most endoscopic spine surgeons $[\mathbf{1 , 8 , 1 2 , 1 3}]$. We found that, this position make it more easy in handling the surgical instruments with 30 to 45 degrees to the horizontal plane.

Making the incision perpendicular to the midline while opening the fascia parallel to the midline will fix the port in place by holding it at 2 different points with 2 different directions and also will prevent mal direction of the port during insertion.

The 2 nd needle kept at the facet always ensure us from correct level without the need for further images taken during surgery after toweling of the patient. Also sliding the port subperiosteally along the spinous process, instead of just go transmuscular, will prevent the port from maldirection away from the lamina toward the facet which may occur in case we introduce it though the muscle.

Having the scope attached to the scope holder and not attached to the working channel, made it easy to navigate with the scope and explore each corner in the field by just freeing the joints of the scope holder and tighten them again to the new position.

Casimiro et al., found that the degree of muscle dissection and the extent of bone fenestration, significantly less than that with microsurgical discectomy [1]. Although, no comparison has been made in our study between this technique and microsurgical techniques, we found more limited bony work and less muscle dissection over microsurgical discectomy.

Casimiro etal reported an average NRS of 1.5 for low back pain achieved after just the 1 st week after the endoscopic surgery [1]. In our small study we found an average NRS for back pain improved to 2 after the 1 st week. Leg pain relieve also was found on an average NRS of 1 after the ${ }^{1 \text { st }}$ week in our study, compared to 0.3 in other studies $[1,14]$.

The QRS quantifies the ability of the patient to perform their normal daily activity $[\mathbf{1 5 , 1 6}]$, thus it reflects the possibility of faster return to work after surgery. In our study functional recovery was significantly good. The average QDS dropped from 58 to 16 by the 4 th week post operatively. Similar results have been reported in the literature by others $[1,17]$.

Although the full endoscopic technique for the treatment of lumber disc herniation has been advocated by many authors $[\mathbf{9 , 1 7 ]}$, in systemic review Rasouli etal reported poorer results with minimally invasive procedures when compared to current microsurgical technique. This was related mainly to smaller extent of decompression and learning curve related issues [18] In our study we found the 2 hands control of the instrument, the panoramic view offered by the endoscope together with using our familiar microsurgical skills, overcome all the problems reported by Rasouli et al.

The mean duration of surgery in our study was 75 minutes, compared to 49 minutes reported by Soman et al., [17], and to 66 minutes reported by Perez-cruet [19].

Operative complications encountered in our study were one case of intra operative dural tear and another case of accumulation of small amount of epidural blood. Similar complications have been reported in the literature but comparison is difficult due to small number study. Post operative hospital stay was about 24 hours. Same results have been reported in the literature $[\mathbf{1 7 , 2 0 ]}$.

Recurrent disc herniation occurred in 2 patients $(13.3 \%)$ in this study. One of them although showed recurrent disc in post operative MRI, he was clinically free of pain. This high incidence of recurrent disc herniation mostly related to young age of the patient, which has been reported in the literature with minimally invasive techniques more than open surgical techniques [17] 


\section{Limitation of the study:}

This study is limited by small number of patients and the need for comparison with microsurgical discectomy. However, in our study we reported our early experience in the full endoscopic discectomy using simple tools as has been described.

\section{Conclusion:}

The endoscopic interlaminar discectomy is an efficient surgical technique for management of unilateral radiculopathy caused by lumber disc herniation and lateral recess stenosis. The panoramic view offered by the endoscope together with much the less muscle dissection and small incision makes this technique much better than conventional surgery.

This study supports that the endoscopic spine surgery can be done using simple tools without the need for highly expensive endoscopic spine tubular systems offered by the spine companies that may not be available at many institutions.

\section{Declarations:}

\section{Acknowledgment:}

The authors thank all included patients.

\section{Funding:}

This study had no funding from any resource.

\section{Competing interests:}

The authors declare that they have no conflict of interest.

\section{Ethical approval:}

This research accepted by Research Ethics Committee (REC) of Faculty of Medicine, Benha University (chairman: Prof/ Ibrahim El-Gendy).

All procedures performed in studies involving human participants were in accordance with the ethical standards of the institutional and/or national research committee and with the 1964 Helsinki declaration and its later amendments or comparable ethical standards. A written informed consent was obtained from each patient after explaining all steps of this study.

\section{Authors' contributions:}

Mohamed Eltantawy performed the operation and clinical part of the study, analyzed the data and wrote with meticulous revision of the paper.

\section{References}

1- CASIMIRO M.: Short-Term Outcome Comparison Between Full-Endoscopic Interlaminar Approach and Open
Minimally Invasive Microsurgical Technique for Treatment of Lumbar Disc Herniation. World Neurosurg. Dec., 108: 894-900, 2017.

2- DASENBROCK H.H., JURASCHEK S.P., SCHULTZ L.R., et al.: The efficacy of minimally invasive discectomy compared with open discectomy: A meta-analysis of prospective randomized controlled trials. Journal of neurosurgery. Spine, 16: 452-62, 2012.

3- BIRKENMAIER C., KOMP M., LEU H.F., et al.: The current state of endoscopic disc surgery: Review of controlled studies comparing full-endoscopic procedures for disc herniations to standard procedures. Pain Physician., 16: 335-44, 2013.

4- CHOI K.C., KIM J.S. and PARK C.K.: Percutaneous Endoscopic Lumbar Discectomy as an Alternative to Open Lumbar Microdiscectomy for Large Lumbar Disc Herniation. Pain. Physician., 19: E291-300, 2016.

5- CONG L., ZHU Y. and TU G.: A meta-analysis of endoscopic discectomy versus open discectomy for symptomatic lumbar disk herniation. European Spine Journal, 25: 134-43, 2016.

6- HIRAIZUMI YUTAKA, posterior endoscopic discectomy using using endoscopic lumber discectomy system (ELDS). J. Musculoskelet. Res., Volume 08, Issue 01, March 2004.

7- FREUDENSTEIN D., DUFFNER F. and BAUER T Novel retractor for endoscopic and microsurgical spinal interventions. Minim Invasive Neurosurg. Jun., 47 (3): 190-5, 2004

8- SONG H., HU W., LIU Z., HAO Y. and ZHANG X. Percutaneous endoscopic interlaminar discectomy of L5$\mathrm{S} 1$ disc herniation: A comparison between intermittent endoscopy technique and full endoscopy technique. J. Orthop. Surg. Res. Oct., 30, 12 (1):162, 2017.

9- FENG F., XU Q., YAN F., XIE Y., DENG Z., HU C., ZHU X. and CAI L.: Comparison of 7 Surgical Interventions for Lumbar Disc Herniation: A Network Metaanalysis. Pain Physician. Sep., 20 (6): E863-E871, 2017.

10- MIXTER W. and BARR J.: Rupture of the intervertebral disc with involvement of the spinal canal. N. Engl. J. Med., 211: 205-210, 1934.

11- Blamoutier A. Surgical discectomy for lumbar disc herniation: Surgical techniques. Orthop. Traumatol. Surg. Res. 99: S 187-S196, 2013.

12- KULKARNI A.G., BASSI A. and DHRUV A.: Microendoscopic lumbar discectomy: Technique and results of 188 cases. Indian J. Orthop., 48: 81-7, 2014.

13- LI M., YANG H. and YANG Q.: Full-Endoscopic Technique Discectomy Versus Microendoscopic Discectomy for the Surgical Treatment of Lumbar Disc Herniation. Pain Physician. Jul-Aug., 18 (4): 359-63, 2015.

14- RUETTEN S., KOMP M., MERK H., et al.: Fullendoscopic interlaminar and transforaminal lumbar discectomy versus conventional microsurgical technique: A prospective, randomized, controlled study. Spine., 33: 931-9, 2008

15- CRUZ E.B., FERNANDES R., CARNIDE F., et al.: Crosscultural adaptation and validation of the Quebec Back Pain Disability Scale to European Portuguese language. Spine, 38: E1491-7, 2013. 
16- KOPEC J.A., ESDAILE J.M., ABRAHAMOWICZ M., et al.: The Quebec Back Pain Disability Scale. Measurement Properties. Spine., 20: 341-52, 1995.

17- SOMAN S.M., MODI J.V. and CHOKSHI J.: Feasibility of endoscopic discectomy by inter laminar approach at a high volume tertiary public hospital in a developing country. J. Spine. Surg., 3 (1): 38-43, 2017.

18- RASOULI M.R., RAHIMI-MOVAGHAR V., SHOKRANEH F., et al.: Minimally invasive discectomy versus microdiscectomy/open discectomy for symptomatic lumbar disc herniation. The Cochrane database of systematic reviews: Cd010328, 2014.

19- PEREZ-CRET M.J., FOLEY K.T., et al: Microendoscopic lumber discectomy. Technical note. Neurosurgery, 51 (Suppl 2): 129-136.

20- RANJAN A., LATH R.: Microendoscopic discectomy for prolapsed lumbar intervertebral disc. Neurol. India., 54: 190-4, 2006.

\section{استئصال للغضروف بالمنظار بإستخدام تقنية بسيطة مونة

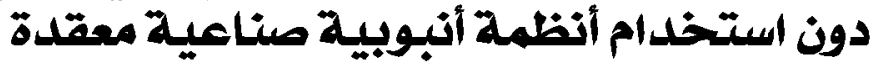

الخلفية: الاستئهال الكامل للغضروف بالمنظار والميكروبكوب هو الأكثر استخداماً على نطاق واسع للتقنيات الغير الغازية

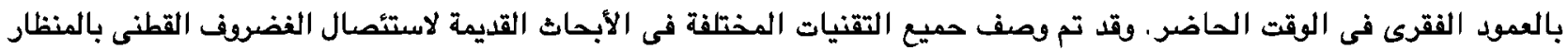

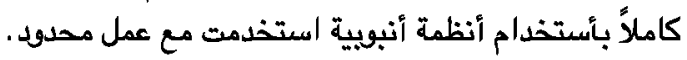

الهدف: لتقييم التقنية الجراحية المعدلة من استئصال الغضروف بالمنظار باستخدام منفذ بسيط وبسينوبكوب عادى دون استخدام أنظمة أنبوبية صناعية معقدة.

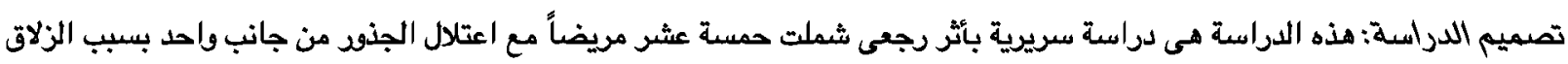

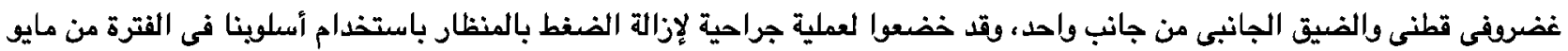

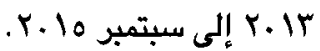

الطريةة: تم تعليل النتائج باستخدام شدة الألم ومقاييس تقيبم النتائج الوظيفية قبل وبعد الجراحة. تم تحليل المضاعفات النتائج الاشعاعية.

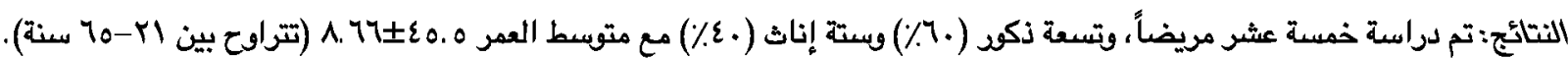

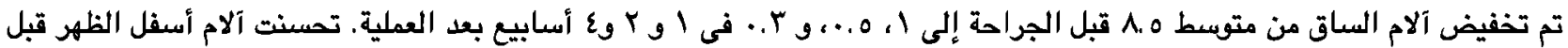

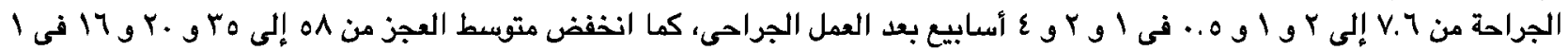
و بو ع أسابيع بعد العمل الجراحى.

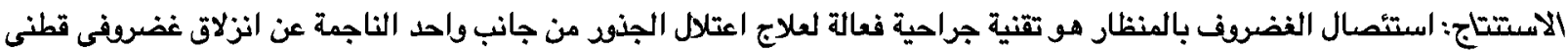

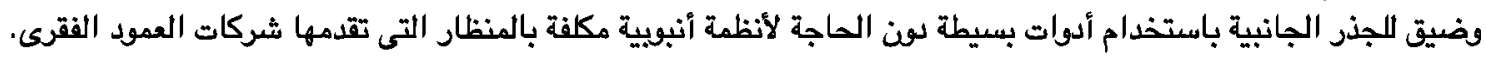

